\title{
Effect of physical activity intervention based on a pedometer on physical activity level and anthropometric measures after childbirth: a randomized controlled trial
}

\author{
Masumeh S Maturi ${ }^{1}$, Pourandokht Afshary ${ }^{2 *}$ and Parvin Abedi $^{2+}$
}

\begin{abstract}
Background: Pregnancy and childbirth are associated with weight gain in women, and retention of weight gained during pregnancy can lead to obesity in later life. Diet and physical activity are factors that can influence the loss of retained pregnancy weight after birth. Exercise guidelines exist for pregnancy, but recommendations for exercise after childbirth are virtually nonexistent. The aim of this study was to evaluate the effect of physical activity intervention based on pedometer on physical activity level and anthropometric measures of women after childbirth.

Methods: We conducted a randomized controlled trial in which 66 women who had given birth 6 weeks to 6 months prior were randomly assigned to receive either a 12 week tailored program encouraging increased walking using a pedometer (intervention group, $\mathrm{n}=32$ ) or routine postpartum care (control group, $\mathrm{n}=34$ ). During the $12-$ week study period, each woman in the intervention group wore a pedometer and recorded her daily step count. The women were advised to increase their steps by 500 per week until they achieved the first target of 5000 steps per day and then continued to increase it to minimum of 10,000 steps per day by the end of $12^{\text {th }}$ week. Assessed outcomes included anthropometric measures, physical activity level, and energy expenditure per week. Data were analyzed using the paired t-test, independent t-test, Mann-Whitney, chi-square, Wilcoxon, covariance analysis, and the general linear model repeated measures procedure as appropriate.

Results: After 12 weeks, women in the intervention group had significantly increased their physical activity and energy expenditure per week (4394 vs. 1651 calorie, $p<0.001$ ). Significant differences between-group in weight ( $P$ $=0.001)$, Body Mass Index $(P=0.001)$, waist circumference $(P=0.001)$, hip circumference $(P=0.032)$ and waist-hip ratio $(P=0.02)$ were presented after the intervention. The intervention group significantly increased their mean daily step count over the study period (from 3249 before, to 9960 after the intervention, $p<0.001$ ).
\end{abstract}

Conclusion: A physical activity intervention based on pedometer is an effective means to increase physical activity; reducing retention of weight gained during pregnancy and can improve anthropometric measures in postpartum women.

Trial registration: ISRCTN: IRCT201105026362N1

\footnotetext{
* Correspondence: p_afshary@yahoo.com

+ Contributed equally

${ }^{2}$ Midwifery School, Ahvaz Jondishapur University of Medical Sciences, P.O.

Box 61357-15794, Ahvaz, Iran

Full list of author information is available at the end of the article
} 


\section{Background}

Pregnancy, childbirth, and the postpartum period are important times in the reproductive lives of women. Pregnancy triggers many physical changes in a woman's body, including weight gain and water retention [1]. The Institute of Medicine (IOM) has updated their guidelines for weight gain during pregnancy according to the WHO recommendations, which are based on the woman's Body Mass Index (BMI) before pregnancy. The current recommended weight gain during pregnancy is $11.5-16 \mathrm{~kg}$ for women with a normal BMI, and 5-9 kg for obese women [2]. Recent studies have shown that pregnant Iranian women typically gain more weight than is recommended by the IOM [3].

Retention after childbirth of weight gained during pregnancy can lead to obesity both during the reproductive years and in later life [4]. The mean retained pregnancy weight 6 months after birth is between 0.5 to 3.8 kg [3]. Physical inactivity and an unhealthy diet contribute to weight retention and obesity after childbirth [5]. For many women, pregnancy is a trigger for weight gain [6]. The factors most involved in retention of weight gained during pregnancy after birth are: BMI before pregnancy, weight gain during pregnancy, smoking cessation, diet, physical activity level and number of pregnancies [7]. Most of these are modifiable. A recent survey in Iran showed that diet and physical activity are the most important modifiable factors involved in pregnancy weight retention after childbirth [8]. Physical activity for at least for $30 \mathrm{~min}$ on most days is critical for general health [9]. According to the 2008 physical activity guidelines for Americans, healthy women should get at least 150 minutes ( 2 hours and 30 minutes) per week of moderate-intensity aerobic activity, such as brisk walking, during and after their pregnancy. It is best to spread this activity throughout the week [10]. In general, better maternal well-being is found among women who maintain or increase their physical activity level from pre-pregnancy to the postpartum period [11]. In the Stockholm study on pregnancy and weight loss, women who retained more weight 1 year after childbirth were less likely to report regular exercise [12]. A systematic review of six trials involving a total of 245 women showed that women who exercised during the postpartum period did not lose significantly more weight than women in the usual care group [13]. A survey of 161 pregnant and postpartum women showed that they were interested in weight-loss interventions and wanted opportunities to exercise with others and receive dietary advice in an educational setting [14]. Another study showed that overweight women with a low activity level undertook significantly more physical activity when they had a daily 10,000 step goal using a pedometer than when they were asked to achieve 30 minutes of walking/day [15]. The results of review of pedometer-based intervention studies has done by the National Institute for Health and Clinical Excellence (NICE) between 1990 and 2005 showed that pedometers may be useful to encourage people increasing their walking [16]. Another systematic review which recruited eight randomized controlled trial and 18 observational studies showed that using pedometer was associated with significant increase in physical activity, decreases in BM I and blood pressure [17]. Both reviews provide support for the suggestion that pedometers may be useful motivational tools for increasing walking. Pedometers are most sensitive to walking behaviors, which is consistent with public health and clinical approaches to increasing physical activity. Specifically, they offer an affordable and accessible technology that is simplistic in output, low-literacy friendly, and immediately understandable to end-users [18]. However, there are several limitations with the reviewed articles; studies were predominantly of short duration $(<12$ weeks) and based in the United States of America. Exercise guidelines exist for pregnancy, but recommendations for exercise during the postpartum period are virtually nonexistent [19]. Strategies to achieve a healthy body weight among postpartum women have not been adequately evaluated. The primary aim of this study was to determine the effect of physical activity intervention program emphasizing walking using a pedometer on physical activity level and anthropometric measures in women after childbirth.

\section{Methods}

This multicenter randomized controlled trial was conducted in seven Health Clinics in the city of Abadan, located in southwest Iran, from June to December 2010. Sample size calculation carried out using a formula recommended by previous studies: $\mathrm{d}=\Delta / \mathrm{SD}$, where " $\mathrm{d}$ " is standardized difference, $\Delta$ is the smallest clinically significant difference and SD is standard deviation of the test group. Power was set at 0.8; Alpha level was set at 0.05 and confidence interval set at $95 \%$. According to the Harris et al's study [4], and changes in the BMI after physical activity, considering $\mathrm{SD}=0.93, \Delta=0.82$, that for more confidence we consider $\Delta=0.5$ and calculated "d" was 0.53 , the sample size calculated 28 for each group with adding 30\% attrition size it changed to 35 women in each group.

\section{Participants}

Initial screening was done on 264 women who had given birth between 6 weeks and 6 months prior, 70 of whom met the trial criteria and agreed to participate. Participants were randomly classified into two groups. One group underwent a 12 week exercise instruction program using a pedometer $(n=35)$, and the other 
received routine postpartum health care $(\mathrm{n}=35)$. Women who met the criteria for inclusion in the trial were: 18 to 40 years old, literate, breastfeeding mothers, who had given birth to a singleton fetus, and who were categorized as physically inactive or low physical activity by the International Physical Activity Questionnaire [20]. Women with preeclampsia, musculoskeletal disorders, or an abnormal BMI before pregnancy $(19.8 \leq \mathrm{BMI}$ $\geq 29$ ) were excluded. BMI was ascertained by maternal self-report at the first prenatal visit. The study was approved by the Ethics Committee of Ahvaz Jondishapur University of Medical Sciences (File No: U89187). Written informed consent was obtained from all participants prior to the study. Health clinics have chosen by stratified method and group allocation was achieved through computer generated randomized sequencing. Researchers were blinded to group allocation and it was done with the party who was not aware of this study. One of the researchers (MM) was responsible to train and follow-up participants after recruitment.

\section{Intervention}

Women in the intervention group were asked to wear a pedometer at all times except when sleeping or bathing. The average of baseline steps in the intervention group was 3,249 , by considering 10,000 as a final target; participants in the intervention group were advised to increase their steps by 500 per week [21] until they reached the first target of 5000 steps per day [22]. Participants advised to continue to increase their steps to minimum 10,000 by the end of $12^{\text {th }}$ week, and to record their daily number of steps in a calendar. An average of the first three days of normal ambulation served as an individual baseline. The pedometer was reset to zero at the beginning of each day by participants. Participants recorded the pedometer readings (steps/day) on a calendar provided by the researcher. At the baseline visit, participants had an individualized counseling session with one of the researchers (MM). During this session women in the intervention group discussed the benefits of physical activity and also benefits of using pedometer. Participants received a reminder about physical activity by cell phone text message once weekly, a phone call once every 2 weeks, and a pamphlet by the name of "losing weight is so easy" by the $8^{\text {th }}$ week. The telephone counseling was designed to provide regular, credible, individualized counseling. During the first few minutes of each telephone counseling call, the researcher asked a woman how many steps she had accumulated each day over the previous week, then provided her with supportive feedback regarding attainment of her physical activity. The pedometers could save information for 1 week. None of participants in the intervention and control groups see each other in time of recruitment in the study (for avoiding contamination).

\section{Outcome Measures}

A socio-demographic questionnaire, a 46 item food frequency intake questionnaire and an International Physical Activity Questionnaire (IPAQ), short version were used to gather data. IPAQ short version (7 questions) was used to assess physical activity across a variety of different domains including leisure-time, domestic, work and transport related physical activity over seven days [20]. Each domain assesses walking, moderate and vigorous physical activity performed for at least 10 consecutive minutes each day, over seven days. An average metabolic equivalent (MET) score was calculated for total physical activity performed per week as a continuous variable whereby total physical activity in MET-minutes/week = sum of total [Walking + Moderate + Vigorous] MET minutes/week scores. Individual MET scores for walking, moderate and vigorous activity were calculated within each domain and combined to provide a total score using the following equations: total METminutes $/$ week $=$ Met-level $\times$ minutes per day $\times$ days per week, where $1 \mathrm{MET}$ is equivalent to resting energy expenditure. According to the IPAQ questionnaire, we classified the physical activity into three categories, if the energy expenditure per week was less than $600 \mathrm{cal}-$ orie, participants classified as light physical activity, if the energy expenditure per week during the last five days was 600 calorie, they classified as a moderate. If the energy expenditure per week reached 1500 calorie during the past 3 days or 3000 calorie during the last 7 days, they classified as vigorous level of physical activity [23].

Participants in the intervention group received a calendar and a pedometer (Omron, HJ-152K-E, China) to record their number of free-living steps per day. This is a valid and reliable method for measuring steps in adult populations [24].

An extensive interview covering socio-demographics, physical activity, and dietary intake in the 6 months prior to the study was performed prior to enrollment in the study, and again at completion of the 12 week study period. The height and body weight of each participant were measured to the nearest $0.5 \mathrm{~cm}$ and $0.1 \mathrm{~kg}$ respectively, while barefooted and in light clothing, using an Omron digital bathroom scale and a SECA stadiometer. BMI was calculated using the formula: BMI = weight $(\mathrm{kg}) /$ height $^{2}(\mathrm{~m})$. BMI was classified into four categories: underweight, < $18.5 \mathrm{~kg} / \mathrm{m}^{2}$; normal, $18.50-24.99 \mathrm{~kg} / \mathrm{m}^{2}$, overweight, $25-29.99 \mathrm{~kg} / \mathrm{m}^{2}$; and obese, $\geq 30 \mathrm{~kg} / \mathrm{m}^{2}$ [25]. Waist measurements were made at the level of minimal trunk girth using a measuring tape. Hip circumference was measured at the level of the greater trochanters. Waist: hip ratio (WHR) was calculated using the formula: WHR = Waist circumference $(\mathrm{cm}) /$ Hip circumference $(\mathrm{cm})$. 
The food frequency questionnaire including 11 food groups and totally 46 items according to the Iranian food composition table was used for assessing food intake of participants pre and post intervention [26]. All interviews and measurements were done by the same researcher (MM).

\section{Statistics}

All data were analyzed using SPSS version 16 . Withingroup changes were assessed using a paired t-test. Between-group differences were assessed using an independent $t$-test for continuous variables and a chi-square test for categorical variables. Spearman correlation coefficients were used to assess the relationship between estimates of physical activity and anthropometric measurements. Exploratory analysis (Kolmogorov- Smirnov test) revealed that baseline data of physical activity were not normally distributed. Non parametric tests were therefore used to analyze these data. Mann-Whitney U test was used for between group differences and Wilcoxon's signed -rank test was used to assess within-group changes over the time. Covariance analysis (ANCOVA) was used to test the health outcomes between-groups after the intervention with initial anthropometric measures as covariates. The general linear model repeated measures procedure was used to assess differences between the number of steps at baseline, days 30, 60 and 90, after the intervention in the intervention group. Differences were considered significant when $p<0.05$.

\section{Results}

Before completion of the 12-week program, three participants from the intervention group and one from the control group withdrew from the study (Figure 1). Table 1 lists the sociodemographic characteristics of the participants. The mean age of participants in the intervention and control groups was 25.7 and 24.8 years, respectively. Many of the participants in both groups had their diploma (46.9\% and $44.1 \%$ for the intervention and control groups, respectively), and most of the women were at a moderate to good economic level. Most of the participants were housewives $(65.5 \%$ of the intervention and $76.5 \%$ of the control group). The majority of women in both groups gained between 12 and $18 \mathrm{~kg}$ during pregnancy $(62.5 \%$ and $50 \%$ in the intervention and control groups, respectively), and the predominant mode of delivery was by cesarean section ( $59.4 \%$ of the intervention group and $64.7 \%$ of the control group).

Weight and BMI of the participants were not different at the beginning of the study (BMI was $26.2 \mathrm{~kg} / \mathrm{m}^{2}$ in the intervention group vs. $25.1 \mathrm{~kg} / \mathrm{m}^{2}$ in the control group, $p>0.05$ ). The food intake of participants did not differ between groups pre- or post-intervention $(p>$ 0.05).

\section{Changes in physical activity}

Weekly physical activity and energy expenditure are shown in Table 2. Before the intervention, the majority of the participants performed only light physical activity (71.9\% and $67.6 \%$ in the intervention and control groups, respectively). After the 12 week study period, $65.6 \%$ of the women in the intervention group and only $32.5 \%$ of the women in the control group were performing vigorous physical activity $(p<0.001)$. Adherence to exercise in the intervention group was excellent; the women started with a mean of energy expenditure of 762.1 calorie per week and progressed to a mean of 4394.3 calorie by week $12(p<0.001)$. The mean energy expenditure per week in the control group was 776 and 1651.4 calorie in weeks 1 and 12, respectively ( $p<$ 0.001). The Mann-Whitney $U$ test showed a significant difference between-groups in physical activity after the intervention ( $p=0.001)$. Figure 2 illustrates pre- and post-intervention descriptive data for the number of steps per day as counted by pedometer. The mean number of steps per day in the intervention group before the study was 3246; after the 12 -week intervention it reached 9960 steps per day $(p<0.001)$ and $62.5 \%$ of participants were performing an acceptable level of physical activity in week 12 .

\section{Changes in the anthropometric measures}

Anthropometric measures before and after the 12 week intervention are reported in Table 3. The intervention group significantly decreased in weight $(66.8 \mathrm{~kg}$ preand $64.7 \mathrm{~kg}$ post-intervention, $p=0.001)$, BMI $(26.28$ $\mathrm{kg} / \mathrm{m}^{2}$ pre- and $25.47 \mathrm{~kg} / \mathrm{m}^{2}$ post-intervention, $p=$ $0.001)$, waist circumference $(80.41 \mathrm{~cm}$ pre- and 76.76 cm post-intervention, $p=0.001$ ), hip circumference $(104.6 \mathrm{~cm}$ pre- and $101.5 \mathrm{~cm}$ post-intervention, $p=$ $0.001)$ and WHR (0.76 pre- and 0.74 post-intervention, $p=0.001$ ) over the study period. ANCOVA revealed significant between-groups differences in anthropometric measures $(p<0.001$ for weight, BMI and waist circumference, $p=0.032$ for hip circumference and $p=$ 0.02 for WHR). There were significant inverse associations between the number of steps per day and changes in weight $(\mathrm{r}=-0.6, p<0.001)$, waist circumference $(\mathrm{r}=$ -0.57, $p=0.001$ ). There was no association between the number of steps per day and changes in hip circumference $(\mathrm{r}=-0.04, p=0.82)$, WHR $(\mathrm{r}=-0.26, p=0.14)$ and BMI $(\mathrm{r}=-0.21, p=0.22)$.

\section{Discussion}

This study investigated the effects of a 12 week tailored program encouraging increased physical activity through the use of a pedometer on anthropometric measures after childbirth. Postpartum visits in Iran typically occur at 10 days and 6 weeks postpartum. These visits cover 


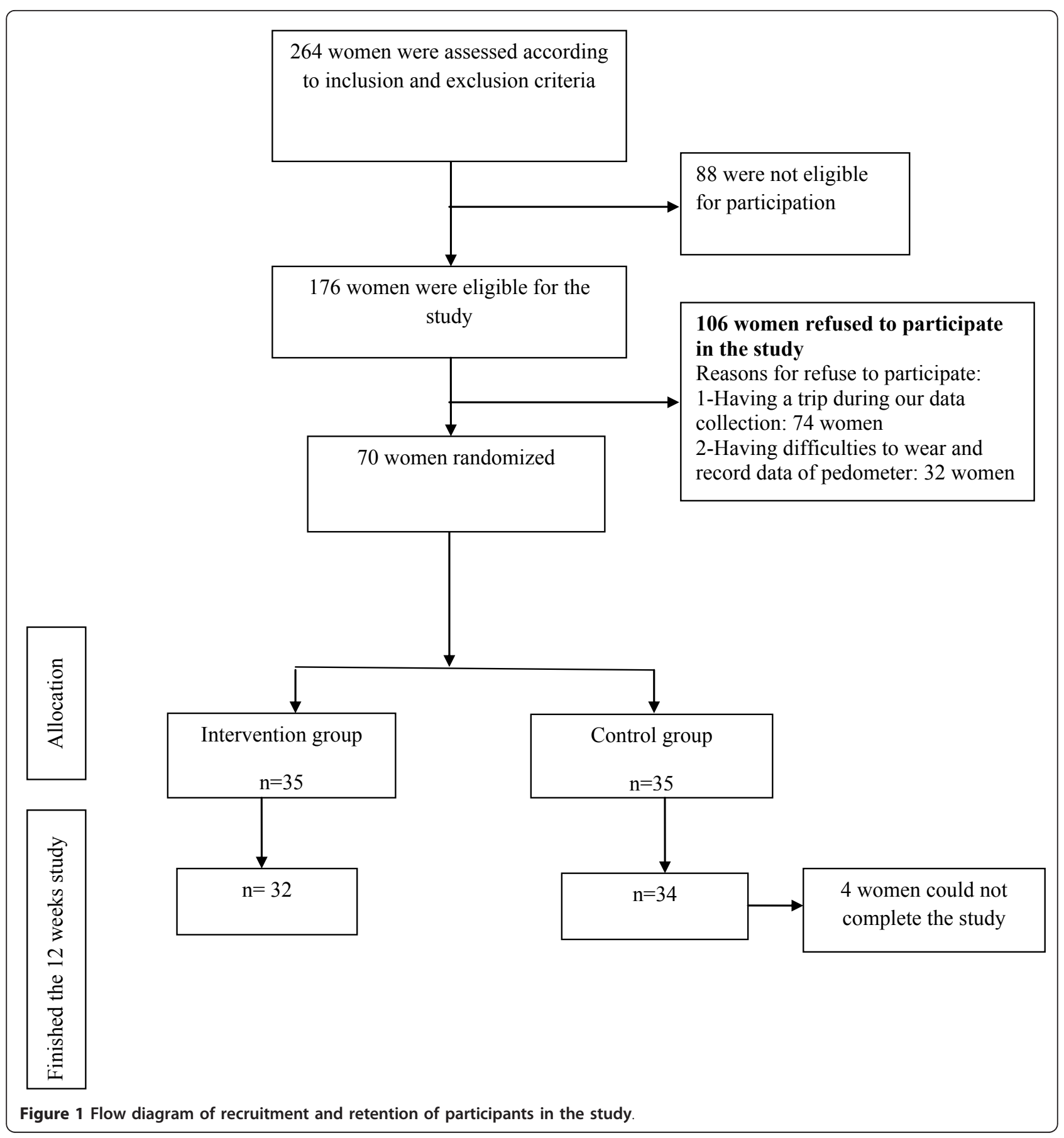

the postpartum changes in the female reproductive system, family planning and breastfeeding. However, advice about weight loss or physical activity is not included in routine postpartum health care. Supporting the first hypothesis of this study, the intervention group demonstrated significant improvement in their physical activity. Pre-intervention responses to the IPAQ indicated that the majority of participants in both groups were performing only light physical activity at the start of the study. After the 12 week intervention none of the women in the intervention group were classified has having a light physical activity level, and they had significantly increased their physical activity level relative to the control group. This finding agrees with the results of other studies [27]. Most of participants in the intervention group had vigorous physical activity after intervention. According to the physical activity recommendations for health and fitness, which also 
Table 1 Baseline characteristics of participants

\begin{tabular}{|c|c|c|c|}
\hline Characteristics & $\begin{array}{l}\text { Intervention group } \\
\mathrm{n}=32\end{array}$ & $\begin{array}{c}\text { Control group } \\
n=34\end{array}$ & $P$ value \\
\hline Age Mean (SD) & 25.7(4.6) & $24.8(3.7)$ & 0.63 \\
\hline Weeks after delivery Mean (SD) & $12.84(5)$ & $12.73(5.86)$ & 0.93 \\
\hline Weight gain during gestation Mean (SD) & $15.96(4.56)$ & 14.3(5.4) & 0.18 \\
\hline \multicolumn{4}{|l|}{ Education $\mathrm{N}(\%)$} \\
\hline High school & $4(12.5)$ & $6(17.6)$ & \\
\hline Diploma & $15(46.9)$ & $15(44.1)$ & 0.63 \\
\hline University education & 13(40.6) & $13(48.2)$ & \\
\hline \multicolumn{4}{|l|}{ Job N(\%) } \\
\hline Working & $7(21.9)$ & $8(23.5$ & 0.66 \\
\hline Housewife & $25(78)$ & $26(76.5)$ & \\
\hline \multicolumn{4}{|l|}{ Parity N(\%) } \\
\hline First & $28(87.5)$ & $31(91.2)$ & \\
\hline Second & $3(9.4)$ & $2(5.9)$ & 0.71 \\
\hline Third and more & $1(3.1)$ & $1(2.9)$ & \\
\hline \multicolumn{4}{|l|}{ Mode of delivery $\mathrm{N}(\%)$} \\
\hline Vaginal & 13(40.6) & $12(35.3)$ & 0.18 \\
\hline Cesarean & 19(59.4) & $22(64.7)$ & \\
\hline
\end{tabular}

apply to postpartum women, a minimum of 40 min of high-intensity physical activity three times per week is sufficient for fitness [28]. The intervention group also could significantly increase their energy expenditure after twelve weeks trial. We also assessed the participants' number of steps per day as counted by a pedometer. After the 12 week trial the women in the intervention group had increased their number of steps per day sufficiently to achieve at least a moderate level of physical activity. Our findings are similar to those reported by Harris, who found that after 12 weeks, women increased their steps to nearly 9000 per day [4].

Supporting the second hypothesis, the intervention group exhibited significant changes in anthropometric measures relative to the control group. This finding agrees with previous researchs that suggests that exercise decreases BMI [29]. It seems that the amount that participants are able to increase their steps per day is not related to their baseline BMI and physical activity based on pedometer can improve anthropometric measures even in overweight and non obese women [30].
This is the first study in Iran to apply both objective (pedometer) and subjective (IPAQ) techniques to assess the effect of physical activity on the anthropometric measures of women after childbirth. As there is currently no routine educational program through Iran's Ministry of Health to increase physical activity after childbirth, women are at risk of permanent weight gain and obesity after childbearing.

Our study has certain limitations. As the purpose of the study was to evaluate the effect of a tailored intervention program on physical activity and anthropometric measurements after childbirth, the results are specific to women in the postpartum period and may not be easily generalized to other populations. Additionally, all the women in this study breastfed their babies. It is well known that the energy requirement during breast feeding increases by 500 calories per day [31]. The data on physical activity levels were collected using the IPAQ, and recall bias may exist. Finally, participants were responsible for writing their number of steps per day in their calendars and the validity of these data

Table 2 Pre- and post-intervention physical activity levels and energy expenditure

\begin{tabular}{|c|c|c|c|c|c|c|c|}
\hline \multirow[t]{2}{*}{ Physical activity } & \multicolumn{2}{|c|}{$\begin{array}{c}\text { Intervention group } \\
n=32 \\
N(\%)\end{array}$} & \multirow[t]{2}{*}{$\begin{array}{l}P \text { value within } \\
\text { group }\end{array}$} & \multicolumn{2}{|c|}{$\begin{array}{c}\text { Control group } \\
n=34 \\
N(\%)\end{array}$} & \multirow[t]{2}{*}{$\begin{array}{l}\text { P value } \\
\text { within } \\
\text { group }\end{array}$} & \multirow[t]{2}{*}{$\begin{array}{l}\mathrm{P} \text { value } \\
\text { between } \\
\text { groups }\end{array}$} \\
\hline & Pre & post & & pre & post & & \\
\hline Light & $23(71.9)$ & 0 & & $23(67.6)$ & $15(44.1)$ & & \\
\hline Moderate & $5(15.6)$ & $11(34.4)$ & 0.001 & $7(20.6)$ & $8(23.5)$ & 0.001 & 0.001 \\
\hline Vigorous & $4(12.5)$ & $21(65.6)$ & & $4(11.8)$ & $11(32.5)$ & & \\
\hline $\begin{array}{l}\text { Energy expenditure per week (Calorie) Mean } \\
\text { (SD) }\end{array}$ & $\begin{array}{l}762.1 \\
(1246)\end{array}$ & $\begin{array}{l}4394 \\
(3001)\end{array}$ & 0.001 & $\begin{array}{l}776 \\
(1070)\end{array}$ & $\begin{array}{l}1651 \\
(1777)\end{array}$ & 0.001 & 0.001 \\
\hline
\end{tabular}




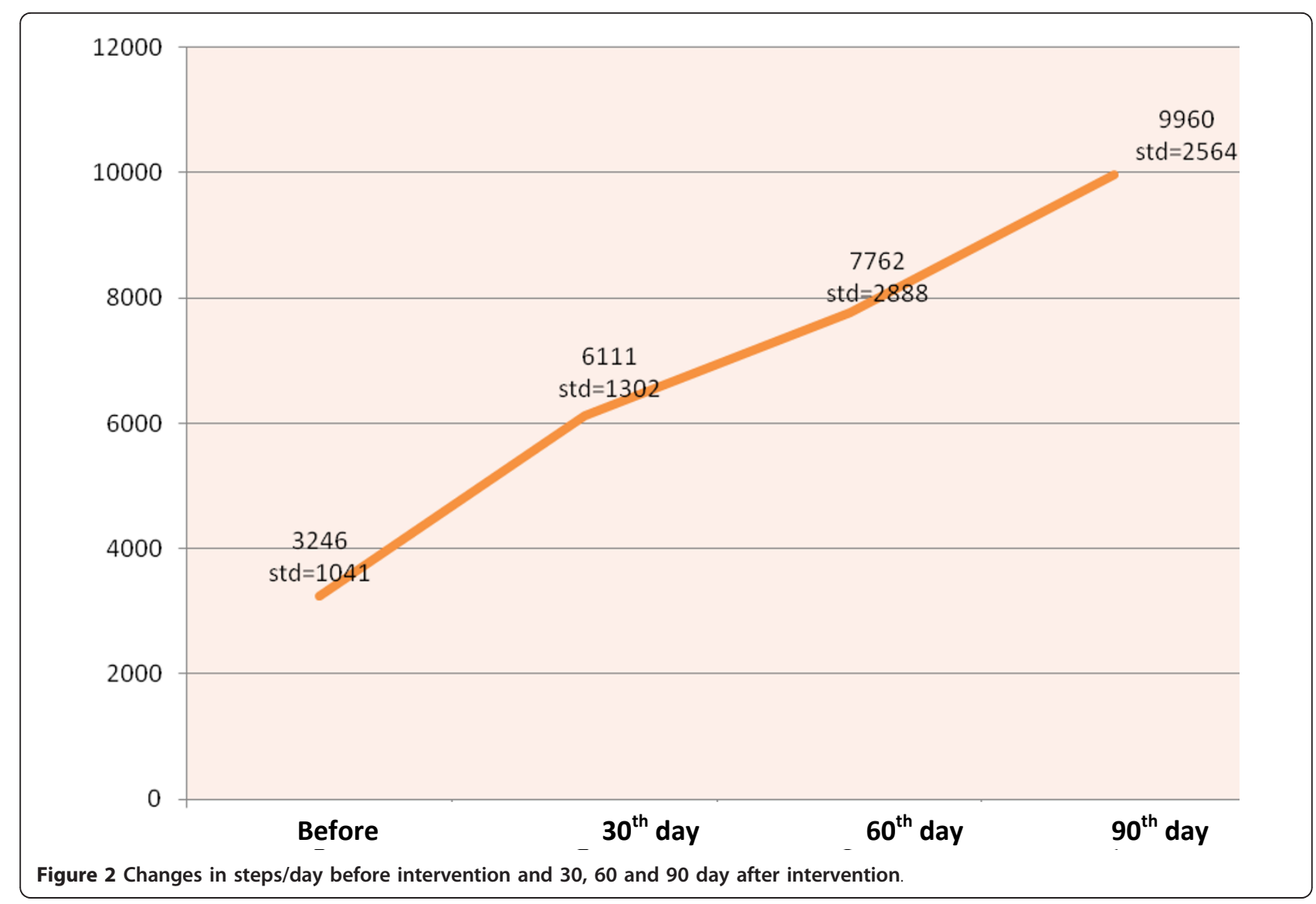

Table 3 Pre- and post-intervention anthropometric measures

\begin{tabular}{|c|c|c|c|c|c|c|c|}
\hline \multirow[t]{2}{*}{ Measure } & \multicolumn{2}{|c|}{$\begin{array}{l}\text { Intervention group } \\
\mathrm{n}=32\end{array}$} & \multirow[t]{2}{*}{$P$ value within group } & \multicolumn{2}{|c|}{$\begin{array}{c}\text { Control group } \\
n=34\end{array}$} & \multirow[t]{2}{*}{$\begin{array}{l}P \text { value } \\
\text { within group }\end{array}$} & \multirow[t]{2}{*}{$\begin{array}{l}\mathrm{P} \text { value } \\
\text { between groups }\end{array}$} \\
\hline & Pre & post & & pre & post & & \\
\hline Weight (kg) & $66.8(8)$ & $64.7(8)$ & 0.001 & $63.9(6)$ & $63.9(6)$ & 0.94 & 0.001 \\
\hline BMI $\left(\mathrm{kg} / \mathrm{m}^{2}\right)$ & $26.2(3)$ & 25.4(3.1) & 0.001 & $25.1(2)$ & $25.2(2.4)$ & 0.69 & 0.001 \\
\hline Waist circumference $(\mathrm{cm})$ & $80.4(5.7)$ & $76.7(5.7)$ & 0.001 & $78.6(4.8)$ & $78.2(4.2)$ & 0.38 & 0.001 \\
\hline Hip circumference $(\mathrm{cm})$ & 104.6(6.8) & $101.5(6.9)$ & 0.001 & $102.4(4.7)$ & 101.2(3.9) & 0.04 & 0.032 \\
\hline Waist hip ratio & $0.76(0.03)$ & $0.74(0.03)$ & 0.001 & $0.76(0.03)$ & $0.77(0.03)$ & 0.31 & 0.02 \\
\hline
\end{tabular}

depends on their honesty. The strength of this study is that it offers an option for increased physical activity compatible with the participants' lifestyles. Participating women could stay home and increase their physical activity while taking care of their babies. Outdoor activity in the hot and humid area of southwestern Iran (the study location) is difficult for almost 6 months a year.

\section{Conclusions}

This study was a novel and comprehensive evaluation of the effect of the physical activity intervention using pedometer on physical activity and anthropometric measures in the postpartum period. The results demonstrated that such tailored programs can successfully encourage women to increase their physical activity and retain less pregnancy weight.

\section{Acknowledgements}

This paper is part of MM's Master's thesis and financial support was provided by the Ahvaz Jondishapur University of Medical Sciences. We would like to thank the Health Clinics of Abadan to their cooperation during data collection. Thanks are also extended to Mr. Haghighizadeh for his assistance with data analysis.

\section{Author details}

${ }^{1}$ Azad University, P.O. Box 666, Abadan, Iran. ${ }^{2}$ Midwifery School, Ahvaz Jondishapur University of Medical Sciences, P.O. Box 61357-15794, Ahvaz, Iran. 


\section{Authors' contributions}

This study is part of the Master's thesis of MM. MM: Design of the study, data collection, analysis and interpretation of data, writing of thesis in Persian. PAF: Design of the study, analysis and interpretation of data, chief investigator of thesis. PA: Design of the study, analysis and interpretation of data, writing and finalizing the manuscript in English, co-supervisor of thesis. All authors are in agreement with the final version of the manuscript.

\section{Competing interests}

The authors declare that they have no competing interests.

Received: 26 July 2011 Accepted: 16 December 2011

Published: 16 December 2011

\section{References}

1. Arthur C, Guyton John E: Textbook of Medical Physiology. Philadelphia: Saunders; 11 2005, 103.

2. Cunningham FG, Norman FG, Leveno KJ, Gilstrap LC, Hauth JC, Wenstrom KD: Williams Obstetrics. USA: McGraw-Hill Professional; 23 2010, 200.

3. Maddah M: Pregnancy weight gaining Iranian women attending a crosssectional study of Public Health Centers in Rasht. Midwifery 2005, 21(4):365-370.

4. Harris V: Physical activity and weight retention in postpartum Black women. Journal of the National Society of Allied Health 2009, 6(7).

5. Linne Y, Barkeling B, Rossner S: Long-term weight development after pregnancy. Obes Rev 2002, 3(2):75-83.

6. Linne Y, Dye L, Barkeling B, Rossner S: Weight development over time in parous women-The SPAWN study-15 years follow-up. International Journal of Obesity 2003, 1516-1522.

7. Kac G, Benício MHDA, Velásquez-Meléndez G, Valente JG, Struchiner CJ: Breastfeeding and postpartum weight retention in a cohort of Brazilian women. American Society for Clinical Nutrition 2004, 79(3):487-493.

8. Kelishadi R, Alikhani S, Delavari A, Alaedini F, Safaie A, Hojatzadeh E: Obesity and associated lifestyle behaviors in Iran: findings from the First National Non-Communicable Disease Risk Factor Surveillance Survey. Public Health Nutrition 2007, 11(3):246-251.

9. Costanzo C, Walker SN, Yates BC, McCabe B, Berg K: Physical activity counseling for older women. West J Nurs Res 2006, 28:786-801.

10. Centers for Disease Control and Prevention (CDC), Physical activity for everyone. 2008, available at: http://www.cdc.gov/physicalactivity/everyone/ guidelines/adults.htm|\#Aerobic.

11. Whatley Blum J, Christina M, Caton-Lemos L: Physical activity patterns and maternal well-being in postpartum women. Maternal and Child Health Journal 2004, 8(3):163-168.

12. Ohlin A, Rossner S: Factors related to body weight changes during and after pregnancy: the Stockholm Pregnancy and Weight Development Study. Obes Res 1996, 4:271-276.

13. Amorim AR, Linne YM, Lourenco PM: Diet or exercise, or both, for weight reduction in women after childbirth. Cochrane Database Syst Rev 2007, 18(3).

14. Østbye T, McBride C, Demark-Wahnefried W, et al: Interest in healthy diet and physical activity interventions peripartum among female partners of active duty military. Mil Med 2003, 168:320-325.

15. Sebely P, Cheryl C, Suleen H: The effect of two different health messages on physical activity levels and health in sedentary overweight, middleaged women. BMC Public Health 2011, 11:204.

16. National Institute for Health and Clinical Excellence (NICE): A rapid review of the effectiveness of pedometer interventions to promote physical activity in adults. London (UK): National Institute for Health and Clinical Excellence (NICE); 2006.

17. Bravata DM, Smith-Spangler C, Sundaram V, Geinger AL, Lin N, Lewis R, Stave CD, Olkin I, Sirard JR: Using pedometers to increase physical activity and improve health. Journal of the American Medical Association 2007, 298(19):2296-2304.

18. Tudor-Locke $C$, Lutes $L$ : Why do pedometers work? A reflection upon the factors related to successfully increasing physical activity. Sports ed 2009, 39(12):981-93.

19. Mottola MF: Exercise in the postpartum period: practical applications. American College of Sports Medicin 2002, 1(6):362-8.
20. Craig C, Marshall AL, Sja-Stra MM, Bauman AE, Booth ML, Ainsowrth BE, et al: International Physical Activity Questionnaire: 12-Country Reliability and Validity. Med Sci Sports Exerc 2003, 35:1381-1395.

21. Montgomery VH: Daily steps and postpartum mood in Black women. Journal of the National Society of Allied Health 2010, 7(8):6.

22. Hultquist CN, Albright C, Thompson DL: Comparison of walking recommendations in previously inactive women. Medicine \& Science in Sports \& Exercise 2005, 37(4):676-683.

23. Guidelines for Data Processing and Analysis of the International Physical Activity Questionnaire (IPAQ) - Short Form Version 2.0. April 2004. Available at: www.ipaq.ki.se

24. Schneider PL, Crouter S, Lukajic O, Bassett D: Accuracy and reliability of 10 pedometers for measuring steps over a 400- $\mathrm{m}$ walk. Med Sci Sports Exerc 2003, 35:1779-1784.

25. World Health Organization: Obesity: preventing and managing the global epidemic. Report of a WHO consultation on obesity. WHO: Geneva; 1998.

26. Azar M, Aminpour A: Traditional and traditional fermented foods in Iran: Fars Province. National Nutrition and Food Technology Research Institute 1998, 57.

27. Albright C, Maddock J, Nigg C: Increasing physical activity in postpartum multiethnic women in Hawaii: results from a pilot study. BMC Women's Health 2009, 9(4):4.

28. American College of Sports Medicine (ACSM): The recommended quantity and quality of exercise for developing and maintaining cardiorespiratory and muscular fitness, and flexibility in healthy adults. Med Sci Sports Exerc 1998, 30:975-991.

29. Østbye T, Katrina M, Krause MA, Cheryl A, Miriam C, Lori A: Active Mothers Postpartum A Randomized Controlled Weight-Loss Intervention Trial. Am J Prev Med 2009, 37(3):173-180.

30. Chan CB, Ryan DAJ, Tudor-Locke C: Health benefits of a pedometer-based physical activity intervention in sedentary workers. Preventive Medicine 2004, 39:1215-1222.

31. Thomson AM, Hytten FE, Billewicz WZ: The energy cost of human lactation. Br J Nutr 1970, 24(2):565-572.

Pre-publication history

The pre-publication history for this paper can be accessed here: http://www.biomedcentral.com/1471-2393/11/103/prepub

doi:10.1186/1471-2393-11-103

Cite this article as: Maturi et al: Effect of physical activity intervention based on a pedometer on physical activity level and anthropometric measures after childbirth: a randomized controlled trial. BMC Pregnancy and Childbirth 2011 11:103.

\section{Submit your next manuscript to BioMed Central and take full advantage of:}

- Convenient online submission

- Thorough peer review

- No space constraints or color figure charges

- Immediate publication on acceptance

- Inclusion in PubMed, CAS, Scopus and Google Scholar

- Research which is freely available for redistribution
C BioMed Central 